\title{
Bioactivity of Active Extracts of Leaf of Bauhinia Racemosa
}

\author{
Ushie O. $A^{1 *}$, Nyong B. $E^{2}$., Tabe $N$. ${ }^{2}$, Jones B.B ${ }^{2}$, Dogara $\mathbf{F}^{1}$ \\ ${ }^{1}$ Department of Chemical Science, Federal University Wukari, Nigeria \\ ${ }^{2}$ Dept of Chemical Sciences, Cross River University of Technology Calabar, Nigeria \\ *Corresponding Author: Ushie O. A, Department of Chemical Science, Federal University Wukari, \\ Nigeria.
}

\begin{abstract}
The leaves of B Racemosa were collected from its natural habitat in Wukari local government area of Taraba state, Nigeria. The method of cold maceration was used in the extraction by serial exhaustive extraction method. The result obtained from antimicrobial activity obtained from the extract of the leave of. $B$. racemosa revealed that not all the extract of leaf of inhibited or exhibited antimicrobial activity against E. coli, Stapyllococus aureus, Salmonella spp, Candida albicans and Aspergillus niger. The result revealed that almost all of the extract exhibited or inhibited antibacterial against E. coli, Stapyllococus aureus, Salmonella spp, Candida albicans and Aspergillus niger, except extract of chloroform and acetone which did not show any inhibition on Salmonella spp $(00.00 \mathrm{~mm})$, extract of chloroform donnot act against Candida albicans and Aspergillus niger, extract of ethanol and ethyl acetate show zero inhibition on Aspergillus niger. Extracts that do not inhibit or exhibit antifungal activity on certain bacterial, have zero zone of inhibitory $(00.00 \mathrm{~mm})$.
\end{abstract}

\section{INTRODUCTION}

Infection diseases are one of the main reasons which cause the death every day. Medicinal plants are used by $80 \%$ of the world population as the only available medicines especially in developing countries, the use of medicinal plants is very wide spread in many parts of the world because it is commonly considered that herbal drugs are cheaper and safer as compared to synthetic drugs and may be used without or minimum side effects. Plants used for traditional medicine contain a wide range of substances that can be used to treat chronic as well as infectious diseases (Subhashini et al., 2010). WHO (2001) defines medicinal plant as herbal preparations produced by subjecting plant materials to extraction, fractionation, purification, concentration or other physical or biological processes which may be produced for immediate consumption or as a basis for herbal products. Ojelere et al.,(2014) point out that medicinal plants are plants containing inherent active ingredients used to cure disease or relieve pain.

One of the criticisms of herbal medicine is lack of standardization and quality control profiles. In addition, there is evidence of herbs been used in the treatment of diseases and for revitalizing the body system in almost all ancient civilization (Manjula et al., 2013). For a long period of time, plants have been a valuable source of natural products for maintaining human health, especially in the last decade, with more intensive studies for natural therapies. In developing countries majority of the people living in rural areas almost exclusively use traditional medicine in treating all sorts of diseases.

The medicinal properties of plants could be based on the antioxidant, antimicrobial antipyretic effects of the phytochemicals in them (Cowman, 1999). Equally, because information on the use of plant species for therapeutic purpose has been passed from one generation to the next through oral tradition, this knowledge of therapeutic plants has started to decline and become obsolete through the lack of recognition by younger generations as a result of a shift in attitude and ongoing social view the valuable.

The plant Bauhinia racemosa is used in traditional medicine for the treatment of various ailments. The stem bark of the plant is an astringent and is used in the treatment of headache, fever, skin diseases and in tumors (Gupta et al., 2004; Kirtikar and Basu, 1975). In Ayurveda the bark is useful for the treatment of malaria, dysentery and diarrhea. The bark and leaves are sweetish and acrid, 
refrigerant, antipyretic, astringent, vermicidal, cure biliousness, urinary discharges, thirst headache, quartan fever, vatta, anal fistula, tuberculous glands, skin dieases, throat troubles, tumors, diseases of the blood, good in chronic dysentery and diarrhea (Anonymous, 1985; Nadkarni and Nadkarni, 2000). The fruit is acrid and sweet; refrigerant and astringent have been isolated from the roots (Jain et al., 2002; Prabhaker et al., 1994). The polar constituents in the ethanol extract of leaves of B. racemosa may be responsible for the antihistaminic activity and B. racemosa may therefore have a role in the treatment of asthma (Nirmal et al., 2011).

For proper understanding of these plants, the medicinal value of the plant most be known, the rightful role at which the plants can play and these plants must be subject to scientific proof base on a proven and phytochemical screening and antimicrobial activities. The traditional medicines have some challenges such as lack scientific proof and lack of prescription. This research gives more insight on the scientific data on the antimicrobial activities of B.Racemosa. To the best of our knowledge little study little or no work have been done on B. Racemosa in this part of the world. This research is useful as it validate that the leaves of $B$. Racemosa are used by traditional practitioner is justifiable are also to be use for medication. However as these research is carried out to justify the traditional uses of plants by carrying out the antimicrobial tests. The aim of this research is to study the determine the bioactive components of the leave of B.Racemosa. as a medicinal plant. The major objectives are; to carry out the antimicrobial test on microorganisms such as Eschrichia coli, Stapyllococus aureus, Salmonella spp, Candida albicans and Aspergillus niger

\section{MATERIALS AND METHODS}

\subsection{Collection Sample and Preparation}

The leaves of B Racemosa were collected from its natural habitat in Wukari local government area of Taraba state, Nigeria. The sample were collected freshly and taken for identification by Biological sciences Department of Federal University Wukari. The leaves were then washed thoroughly in running tape water and then with distilled water. The leaves were cut into small bits and dried for two weeks under shade. After drying, the plant materials were ground well using mechanical blender into fine powder. Then the powder was stored in airtight containers with proper labeling and kept in the laboratory for use.

\subsection{Preparation of Plant Extract}

The method of cold maceration was used in the extraction by serial exhaustive extraction method which involves the successive extraction with solvents in order of their increasing polarity from hexane to ethanol to ensure efficient extraction of wide range of compounds present in the leaves. The leaf extracts were prepared by soaking $200 \mathrm{~g}$ of $400 \mathrm{ml}$ hexane for four days with frequent agitation until soluble matter are dissolved. The resulting mixture was filtered using Whatman No.1 filter paper, evaporated and concentrated into solid extracts using rotatory evaporator, kept under room temperature overnight to remove all solvent. The process was repeated for chloroform, ethyl acetate, acetone and ethanol sequentially in order of increasing polarity. The extracts were kept in a desiccator until required for test.

\subsection{Bioassay}

This is the study of antimicrobial activity of the crude or purified extracts against micro-organism. It was used as a guide to determine the active components of the leaves of $B$. Racemosa. The crude extracts were tested for antibacterial and antifungal activities. The test organisms were collected from Bauchi Specialist Hospital, Bauchi State, Nigeria. The antimicrobial assay was carried out using methods described by Ochi et al., (2015) with modifications.

\subsection{Preparation of varying concentration of extracts}

Various concentration of extracts were prepared ranging from $12.5 \mathrm{mg} / \mathrm{mL}$; this was obtained by measuring $1 \mathrm{mg}$ of extract and dissolved in $10 \mathrm{~mL}$ dimethyl sulphur oxide(DMSO),a solvent that dissolved the extract $(100 \mathrm{mg} / \mathrm{mL})$. A serial dilution of the dissolved extract $((100 \mathrm{mg} / \mathrm{mL})$ was carried out into three different bottles containing DMSO to obtain concentrations of 50,25 and $12.5 \mathrm{mg} / \mathrm{mL}$ respectively.

\subsection{Sensitivity test of crude extact of Agar Well Diffusion Method}

The organisms used were standardized using Mc-Farland turbidity standard scale 1,to obtain a bacterial cell density of 106 colony forming unit milliliter $(\mathrm{cfu} / \mathrm{mL})$. The standardized inoculate were uniformly streaked (swabbed) into freshly prepared Mueller Hinton agar and potato dextro agar 
plates respectively for the bacterial and fungal growth. For wells were punched on the inoculated plate with a cork borer ( $8 \mathrm{~mm}$ in diameter). The wells were properly labeled according to different number of concentration prepared. The well were then fill up with the extracts about $0.2 \mathrm{Ml}$ per well. The plates were allowed to stay on the bench for $1 \mathrm{hr}$ for extract to diffused on the agar. The Mueller Hinton agar plates for bacterial were incubated at $37^{\circ} \mathrm{C}$ for three days were the potato dextro agar plates for fungi were incubated at room temperature (drawer)for three days. At the end of incubation period, all the plates were observed for any evidence of inhibition, which will appear as a clear zones that were completely devoid of growth around the wells (zone of inhibition). The diameters of zones were measured with transparent ruler calibrated in millimeter $(\mathrm{mm})$.

\subsection{Determination of Minimum Inhibitory Concentration (MIC)}

The minimum inhibitory concentration (MIC) of the extract was determined using tube dilution method. Serial dilution of the extract was carried out in test tubes using Mueller Hinton Broth (MHB)and potato Dextro Broth (PDB) as diluents. The lowest concentration showing inhibition (clear zone) for each organism when the extract was tested during sensitivity test was serially diluted in test tubes containing Mueller Hinton Broth (MHB) and potato Dextro Broth (PDB). Each tube containing the broth and the extract was incubated with the standardized organisms. A tube containing sterile broth (MHB and PDB) without any organism been used as a control. All tubes were then incubated $37^{\circ} \mathrm{C}$ for $24 \mathrm{hrs}$. After incubation period, the tube was examined for the presence or absence of growth using turbidity as a criterion. The lowest concentration (dilution) in the series without any visible signs of growth was considered to be the minimum inhibitory concentration (MIC).

\section{RESUlts}

\subsection{Antimicrobial Activities of Bauhinia Racemosa}

\subsubsection{Mean zone of inhibition of crude extract of Bauhinia racemosa}

The activity of hexane, chloroform, ethyl acetate, acetone and methanol crude extracts of Bauhinia racemosa was tested on five clinical isolates and the result of the mean zone of inhibition is presented in Table 1 below.

Table1. Mean zone of inhibition of crude extract of Bauhinia racemosa

\begin{tabular}{|c|c|c|c|c|c|c|c|c|}
\hline $\begin{array}{c}\text { Test } \\
\text { Organism }\end{array}$ & $\begin{array}{l}\text { Conc. } \\
\mathrm{mg} / \mathrm{ml}\end{array}$ & HEBR & CEBR & EAEBR & AEBR & EEBR & $\begin{array}{l}\text { Positive (+) } \\
\text { control } \\
\text { streptomycin }\end{array}$ & $\begin{array}{c}\text { Negative } \\
\text { Control } \\
\text { DMSO }\end{array}$ \\
\hline \multirow[t]{4}{*}{ E-Coli } & 200 & 18.00 & 18.00 & 20.00 & 20.00 & 18.00 & 32.00 & 00.00 \\
\hline & 100 & 16.00 & 17.00 & 19.00 & 19.00 & 17.00 & 28.00 & 00.00 \\
\hline & 50 & 14.00 & 18.00 & 17.00 & 19.00 & 15.00 & 28.00 & 00.00 \\
\hline & 25 & 12.00 & 15.00 & 15.00 & 17.00 & 13.00 & 27.00 & 00.00 \\
\hline \multirow[t]{4}{*}{ St. aureus } & 200 & 18.00 & 18.00 & 17.00 & 17.00 & 17.00 & 17.00 & 00.00 \\
\hline & 100 & 16.00 & 15.00 & 15.00 & 15.00 & 15.00 & 15.00 & 00.00 \\
\hline & 50 & 14.00 & 14.00 & 13.00 & 13.00 & 13.00 & 13.00 & 00.00 \\
\hline & 25 & 12.00 & 13.00 & 11.00 & 13.00 & 10.00 & 10.00 & 00.00 \\
\hline \multirow{4}{*}{$\begin{array}{c}\text { Salmonella } \\
\text { Spp }\end{array}$} & 200 & 19.00 & 00.00 & 17.00 & 00.00 & 20.00 & 30.00 & 00.00 \\
\hline & 100 & 16.00 & 00.00 & 16.00 & 00.00 & 18.00 & 28.00 & 00.00 \\
\hline & 50 & 14.00 & 00.00 & 14.00 & 00.00 & 17.00 & 28.00 & 00.00 \\
\hline & 25 & 12.00 & 00.00 & 13.00 & 00.00 & 15.00 & 26.00 & 00.00 \\
\hline \multirow[t]{4}{*}{$\begin{array}{l}\text { Candida } \\
\text { albican }\end{array}$} & 200 & 23.00 & 00.00 & 22.00 & 22.00 & 23.00 & $\begin{array}{c}\text { Fulcin (+)ve } \\
28.00\end{array}$ & 00.00 \\
\hline & 100 & 21.00 & 00.00 & 20.00 & 20.00 & 21.00 & 26.00 & 00.00 \\
\hline & 50 & 19.00 & 00.00 & 18.00 & 18.00 & 18.00 & 24.00 & 00.00 \\
\hline & 25 & & 00.00 & 17.00 & 17.00 & 17.00 & 23.0 & 00.00 \\
\hline
\end{tabular}




\begin{tabular}{|c|c|c|c|c|c|c|c|c|}
\hline & \multicolumn{2}{|c|}{} & & & & & \\
\hline \multirow{4}{*}{$\begin{array}{c}\text { Aspergillus } \\
\text { niger }\end{array}$} & 200 & 21.00 & 00.00 & 00.00 & 22.00 & 00 & 30.00 & 00.00 \\
\cline { 2 - 9 } & 100 & 19.00 & 00.00 & 00.00 & 20.00 & 00.00 & 28.00 & 00.00 \\
\cline { 2 - 9 } & 50 & 17.00 & 00.00 & 00.00 & 18.00 & 00.00 & 26.00 & 00.00 \\
\cline { 2 - 9 } & 25 & 16.00 & 00.00 & 00.00 & 16.00 & 00.00 & 24.00 & 00.00 \\
\hline
\end{tabular}

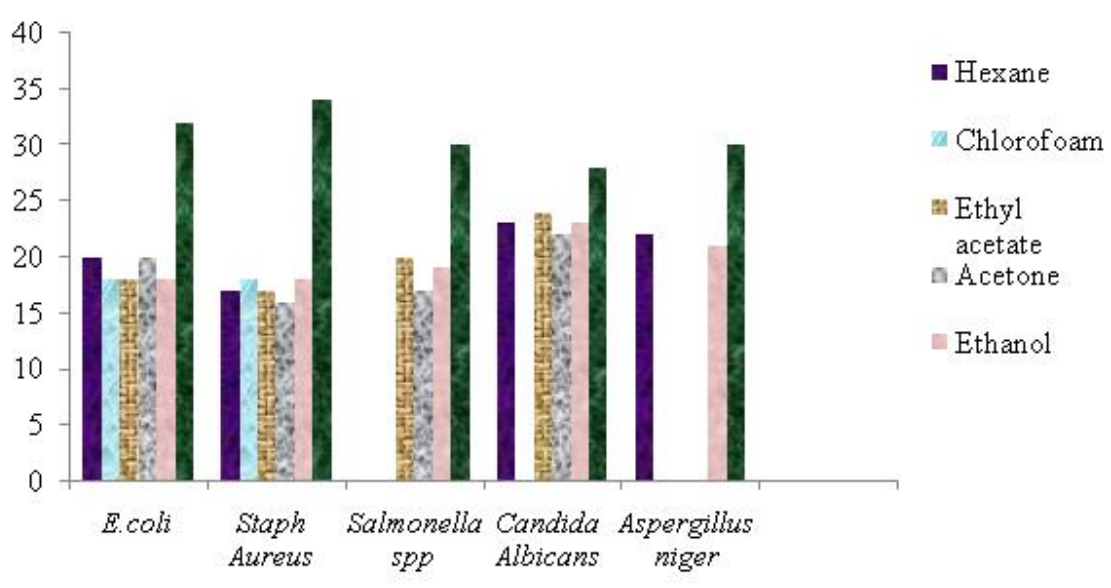

Figure1. Histogram of antimicrobial activities of B. racemosa

Table3. Minimun Inhibitory Concentration (MIC) of crude extract of Bauhinia racemosa

\begin{tabular}{|c|c|c|c|c|c|c|}
\hline S/N & Organism & $\begin{array}{c}\text { MIC } \\
\text { Hexane } \\
(\mathbf{m g} / \mathbf{m l})\end{array}$ & $\begin{array}{c}\text { MIC } \\
\text { Chlorofoam } \\
(\mathbf{m g} / \mathbf{m l})\end{array}$ & $\begin{array}{c}\text { MIC } \\
\text { Ethyl acetate } \\
(\mathbf{m g} / \mathbf{m l})\end{array}$ & $\begin{array}{c}\text { MIC } \\
\text { Acetone } \\
(\mathbf{m g} / \mathbf{m l})\end{array}$ & $\begin{array}{c}\text { MIC } \\
\text { Ethanol } \\
(\mathbf{m g} / \mathbf{m l})\end{array}$ \\
\hline 1 & 25 & 25 & 25 & 25 & 25 & 25 \\
\hline 2 & 25 & 25 & 25 & 25 & 25 & 25 \\
\hline 3 & 25 & 25 & 25 & 25 & 25 & 25 \\
\hline 4 & 25 & 25 & 25 & 25 & 25 & 25 \\
\hline
\end{tabular}

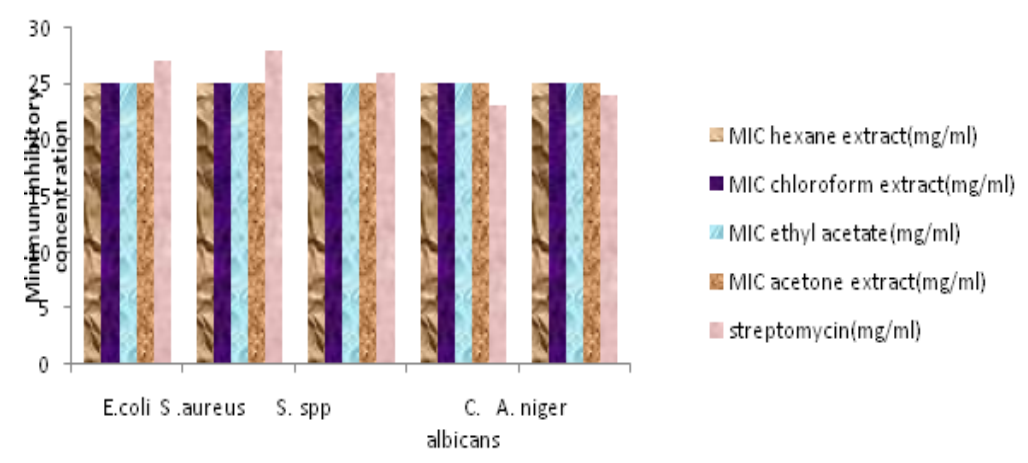

Figure2. Histogram of Minimun Inhibitory Concentration of B. racemosa

\section{DISCUSSION}

The result of antimicrobial activity as shown in Table 1 show the activities of the crude hexane, chloroform, ethyl acetate, acetone and ethanol obtained from extract of leave of $B$ racemasa were tested on five clinical isolates; E. coli, Stapyllococus aureus, Salmonella spp, Candida albicans, Aspergillus niger, while streptomycin and fucin were used as control drugs. The minimum inhibitory activity (MIC) of the extracts of B. racemasa against tested microbes ranges from 25 to $200 \mathrm{mg} / \mathrm{ml}$ in all the extracts against the tested bacteria. The result revealed that almost all of the extract exhibited or inhibited antibacterial against E. coli, Stapyllococus aureus, Salmonella spp, Candida albicans and Aspergillus niger, except extract of chloroform and acetone which did not show any inhibition on Salmonella spp $(00.00 \mathrm{~mm})$, extract of chloroform donnot act against Candida albicans 
and Aspergillus niger, extract of ethanol and ethyl acetate show zero inhibition on Aspergillus niger . Extract that do not inhibit or exhibit antifungal activity on certain bacterial, have zero zone of inhibitory $(00.00 \mathrm{~mm})$ as represented in Table 1 above.. Ethanol extract exhibited the highest activity for Candida albicans test (24 $\mathrm{mm}$ zone diameter of inhibition), followed by Hexane and acetone on the same organism (Candida albicans), (with both having $23 \mathrm{~mm}$ zone diameter of inhibition). Acetone and chloroform extract did not show any activity against Salmonella spp, chloroform extract did not demonstrate any activity against Candida albicans and Aspergillus niger and also both ethanol and ethyl acetate extracts did not act against Aspergillus niger. This result is presented in figure 1 below.

The crude extracts of acetone extract inhibited or exhibited antifungal activity against E. coli, Stapyllococus aureus, , Candida albicans and Aspergillus niger with a diameter that ranged between $13-23 \mathrm{~mm}$ with the highest zone of inhibition of 23 followed by $22 \mathrm{~mm}$ at minimum inhibitory concentration (MIC) at $200 \mathrm{mg} / \mathrm{ml}$, but did not show inhibition on Salmonella spp. Chloroform extract inhibited or exhibited antifungal activity against only two organism (E. coli, and Stapyllococus aureus), with a mininimun zone of inhibition ranges from 13-18mm but did not show inhibition on Salmonella spp, Candida albicans and Aspergillus niger. Ethanol extract inhibited or exhibited antifungal activity against almost all the test organism except on Aspergillus niger, with the minimum zone of inhibition ranging from $10-24 \mathrm{~mm}$ with the highest inhibition on Candida albicans $(24 \mathrm{~mm})$, ethyl acetate just like the ethanol extract inhibited or exhibited antifungal activity against E. coli, Stapyllococus aureus, Salmonella spp, Candida albicans with the minimum zone of inhibition ranging from $11-22 \mathrm{~mm}$ with the highest inhibition on Candida albicans $(22 \mathrm{~mm})$. However, hexane extract show inhibited on all the test organisms E. coli, Stapyllococus aureus, Salmonella spp, Candida albicans and Aspergillus niger ranging from 12-21 $\mathrm{mm}$ with the highest effect on Aspergillus niger $(21 \mathrm{~mm})$. The least activity is observed in ethanol extract with $10 \mathrm{~mm}$ zone of inhibition against Stapyllococus aureus, followed by $11 \mathrm{~mm}$ observed in ethyl acetate extract on Stapyllococus aureus which occur at $25 \mathrm{mg} / \mathrm{ml}$ minimum inhibitory concentration (MIC).

\section{CONCLUSION}

The result obtained from antimicrobial activity obtained from the extract of the leave of. B. racemosa revealed that not all the extract of leaf of inhibited or exhibited antimicrobial activity against $E$. coli, Stapyllococus aureus, Salmonella spp, Candida albicans and Aspergillus niger. Precisely Salmonella spp which acetone and chloroform extract donnot show any antimicrobial activity on as wll as chloroform extract not acting againats both Candida albicans and Aspergillus niger. Ethanol and ethyl acetate extract did not act against Aspergillus niger. Conclusively, the higher the zone of inhibitory the stronger the antimicrobial activity of such extract on that particular organism. Zero zone of inhibitory implies that the extract has no any antimicrobial activity on that organism, from the result obtained in table 4.2 it can be concluded that ethanol extract has the highest antimicrobial activity on Candida albicans ( $24 \mathrm{~mm}$ minimum zone of inhibition).

\section{REFERENCES}

[1] Anonymous (1985). The Wealth of India. (New Delhi, India: National Institute of Science Communications and Information Resources, Council of Scientific and Industrial Research p.114Cowan, M.M. (1999). Plant products as antimicrobial agents. Clin.Microbial.Rev.564-582

[2] Gupta M, Upal KM, Ramanathan SK, Thangavel SK. Antitumor activity and antioxident role of B. racemasa against Ehrlich ascites carcinoma in Swiss albino mice. Acta Pharmacol Sin.2004; 25:10701076.

[3] Jain, S. K (1998). Dictionary of Indian folk medicine and ethno botany. (New Delhi, India: Deep publication), pp. 261-296.

[4] Jain, S.K and De, J.N (1996). Observations on ethnobotany of purila district, West Bengal. Bull Bot Surv India; 8:237-251.

[5] Jain R, Alam S, Saxena UA. A new teteacyclic phenol and other constituents from the roots of Bauhinia racemosa. Indian J Chem. 2002; 41:1321-1322.

[6] Kirtikar KR, Basu BD. Indian medicinal plants. Vol. 2. 2nd ed. (Dehradun, India: Bishen Mahendra pal. singh), 1975

[7] Manjula Gupta, Ankur Kashyap, A.K.Mishra and M. some Plant Product for the Control of Predatory Aquatic Insects. Research Journal of Life Sciences, 01(01), 1-5 Serajuddin (2013).Studies on Insecticidal Effica.

[8] Nadkarni KM, Nadkarni, AK. Indian Material Medica. Vol. 1. 3rd ed. (Bombay, U.K.: Popular Prakashan, Pvt. Ltd), p. 435, 2000 
[9] Nirmal SA, Laware RB , Rathi RA, Dhasade VV, Kuchekar BS.. Antihistaminic effect of B. racemosa leaves. J Young Pharm. 2011;3:129-131.

[10] Ochi I.O Ekirigwe, Lomgbap B.D., Ambiaziem C.V., Tabe N.T. (2015). Physiochemical analysis and antimicrobial screening of dried root of extacto of alchornea cordifolia Ewemen journal of microbial reseaarch (1):25-30

[11] Ojelere, O,; Olusola and Adoge 2014.Evaluation of the phytochemicals and microbial inhibitory properties of piper Guineensii and Buchhlozia coriacea seeds of Nigerian origin.Global journal of medicinal Research: C Microbiology and pathology (14)7.

[12] Rastogi R, Prabhakar P, Gandhidasan R, Raman PV, Krishnasamy NR, Nanduri S. A tetracyclic 2, 2 dimethyl chroman from the roots of Bauhinia racemosa. Phytochemistry. 1994; 36:817-818.

[13] Subhashini R., U.S. Mahadeva R, Sumathi P. and Gayathri G. (2010) A comparative Phytochemical analysis of cocoa and green tea. Indian Journal of Science and Technology (3)2: 0974- 6846.

[14] Ushie, O. A, Egwaikhide,P. A and Longba B. D (2016) Phytochemical Screening and Antimicrobial Activity of Tamarindus indica. International Journal of Traditional and Complementary Medicine. 1 (2): 0010-0017

[15] WHO (2001). Traditional Medicine: Growing Needs and Potential. WHO Policy Perspectives on Medicines World Health Organization, Geneva

[16] WHO (2002). Traditional Medicine: Growing Needs and NPotential. WHO Policy Perspectives on Medicines. World Health Organization, Geneva

Citation: UshieO.A, et.al. (2019). "Bioactivity of Active Extracts of Leaf of Bauhinia Racemosa". International Journal of Clinical Chemistry and Laboratory Medicine (IJCCLM), 5(2), pp. 19-24, DOI: http://dx.doi.org/10.20431/2455-7153.0502004.

Copyright: (C) 2019 Authors. This is an open-access article distributed under the terms of the Creative Commons Attribution License, which permits unrestricted use, distribution, and reproduction in any medium, provided the original author and source are credited. 